\title{
Analysis of heat transfer in a coated bed of an adsorption chiller
}

\author{
Karolina Grabowska ${ }^{1, *}$, Marcin Sosnowski ${ }^{1}$, Jaroslaw Krzywanski ${ }^{1}$, Karol Sztekler ${ }^{2}$, Wojciech Kalawa ${ }^{2}$, Anna Zylka ${ }^{1}$, \\ and Wojciech Nowak ${ }^{2}$ \\ ${ }^{1}$ Faculty of Mathematics and Natural Science, Jan Dlugosz University, al. Armii Krajowej 13/15; PL42-200 Częstochowa, Poland \\ ${ }^{2}$ AGH University of Science and Technology, al. A. Mickiewicza 30; PL30-059 Cracow, Poland
}

\begin{abstract}
Adsorption chillers can be a promising part of sustainable development concept of the global economy due to the utilization of low grade thermal energy sources for cooling production. Therefore, research aiming at improving their performance i.e. Coefficient of Performance (COP) by optimizing the heat and mass transfer condition in the adsorption beds are crucial. Innovative modification of the sorbent layer structure are proposed in the paper in order to improve the heat transfer characteristics in the heat exchanger boundary layer. The analysis of desorption conditions in the parametric model of a coated adsorption bed construction is presented in the paper. The computational fluid dynamics with conjugate heat transfer analysis are used to determine the crucial input parameters for further analytical calculations. The heat transfer condition in novel coated design and a conventional fixed bed are compared in the paper. The developed computational model consisted of three subdomains representing heating water, heat exchanger material (copper) and sorbent (silica gel).
\end{abstract}

\section{Nomenclature}

(in) - inlet

(out) - outlet

$\lambda$ - Thermal Conductivity; $\mathrm{W} /(\mathrm{m} * \mathrm{~K})$

$\mathrm{T}_{\mathrm{w}}$ - average temperature of hot water; $\mathrm{K}$

$\mathrm{T}_{\mathrm{S}}$ - average temperature of silica gel; $\mathrm{K}$

$\mathrm{T}_{\mathrm{c}}$ - average temperature of coated layer; $\mathrm{K}$

\section{Introduction}

Industrial waste heat, solar power and heat from cogeneration are ecological sources suitable to power adsorption chillers [1-3]. It is the best strategy to reduce consumption of conventional energy, because the compressor air conditioning devices are mostly very high electrical energy consuming systems. Therefore research on improving adsorption cooling technology efficiency is a crucial task to sustainable economic development.

Currently the low coefficient of performance (COP) of adsorption chillers limits the dissemination of this technology. High thermal resistance in the vicinity of a heat exchanger surface, which is the result of the high porosity of a fixed sorbent layer is responsible for the low heating power (HP) of the bed [4]. Therefore the crucial area of chiller optimization is to improve the heat transfer coefficient between the adsorbent bed and the heat transfer surface.

In a paper [5] to improve the heat transfer conditions, polydispersive sorbent structures were investigated. The porous media was mixed with metal filings which are characterized by higher thermal conductivity.

A new approach to bed modification is using a coated bed construction [6] where the sorbent layer is glued to the heat exchanger surface. The glue with good thermal parameters, fills the gaseous spaces between particles and reduces the thermal contact resistance of the heat exchanger boundary layer. The optimal parameters of components used to build the novel coated bed construction was defined in [7]. Another important concept of improving the adsorption chiller efficiency is further developing of the heat exchanger surface. Finned tubes of various shapes are investigated in [8-10]. Complementing the heat transfer experimental studies in the sorbent bed is modeling research based on computational fluid dynamics (CFD) and artificial intelligence (AI) methods [11-13].

A validated CFD model was used to optimize the adsorption cooling cycle based on activated carbon ethanol pair in [14]. In paper [15] silica gel-water working pair was analyzed numerically. The innovative discretization method, which can be used in numerical modeling of flow within granular materials like porous media was presented in $[16,17]$.

The goal of this paper is to develop a numerical model of heat transfer in the adsorption bed of modified coated construction.

\footnotetext{
* Corresponding author: k.grabowska@ujd.edu.pl
} 


\section{Analysis and modelling}

\subsection{Experimental study}

In order to develop the adsorption bed model, thermal parameters of the porous media layer were defined experimentally. Measurements of heat conductivity $\lambda$ was carried out with the use of a LFA 457 MicroFlash ${ }^{\circledR}$ apparatus by Netzsch company which performs precise thermal diffusivity measurements based on the Laser Flash Methods (LFM).

The thermal conductivity of fixed and coated sorbent samples were examined. Silica gel was used as a sorbent and an epoxy resin was used as a glue material. The results of experimental tests are presented in Table 1. As it can be seen from table, fixed layer of porous media is characterized by significantly lower thermal conductivity than the coated layer.

Table 1. Thermal conductivity of sorbent samples

\begin{tabular}{|c|c|c|c|}
\hline Samples & $\begin{array}{c}\boldsymbol{\lambda} \\
(\mathbf{W} / \mathbf{m} * \mathbf{K})\end{array}$ & $\begin{array}{c}\text { Specific } \\
\text { Heat } \\
\left(\mathbf{J} / \mathbf{k g} \mathbf{k}^{*}\right)\end{array}$ & $\begin{array}{c}\text { Bulk Density } \\
/ \mathbf{D e n s i t y} \\
(\mathbf{g} / \mathbf{c m} \mathbf{3})\end{array}$ \\
\hline $\begin{array}{c}\text { fixed sorbent } \\
\text { layer }\end{array}$ & 0.18 & 924 & 0.8 \\
\hline $\begin{array}{c}\text { coated } \\
\text { sorbent layer }\end{array}$ & 0.48 & 700 & 0.8 \\
\hline
\end{tabular}

\subsection{Numerical geometry}

The numerical geometry of the adsorption bed was built with a basic component repeated 60-times, one after another along the axis, which is presented in Figure 1.

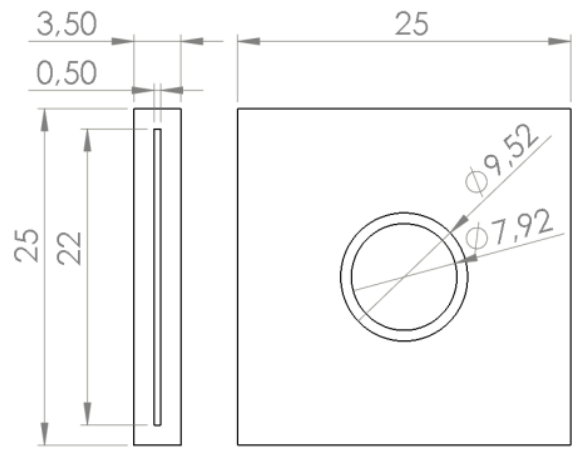

Fig. 1. The basic component of the adsorption bed model.

A 3D model of the adsorption bed was created with the use of the above geometry and it was used to perform the numerical simulations. The adsorption bed model consisted of three computational subdomains representing respectively heating water, heat exchanger material (copper) and silica gel or coated silica gel layer dependent on the analyzed case, such as presented in Figure 2. The temperature distribution was analyzed in a computational domain composed of heat exchanger (finned cooper pipe) with a length of $210 \mathrm{~mm}$ and a width of $125 \mathrm{~mm}$ (5 components with a width of $25 \mathrm{~mm}$ each).

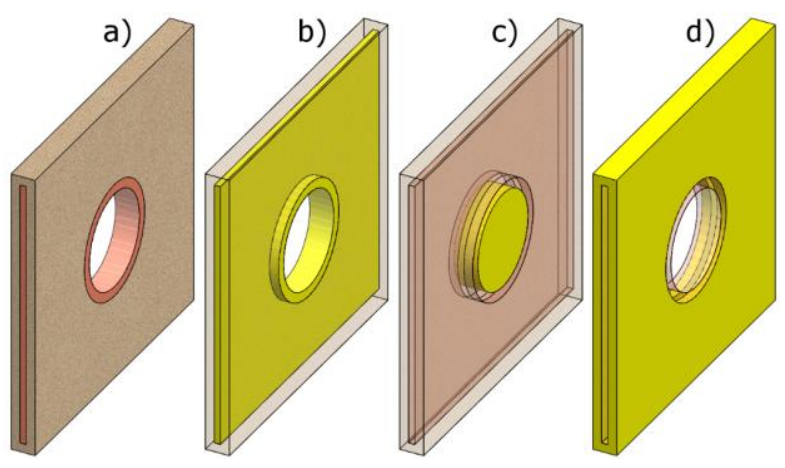

Fig. 2. Computational domains: a) entire domain, b) metal, c) water, d) silica gel or coated silica gel.

This geometry is characterized by the repeatability of the layout of finned tubes, therefore in order to minimize calculation time, the model was reduced by using periodicity condition. The simulation were carried out on a model reduced to the form as presented in Figure 3.

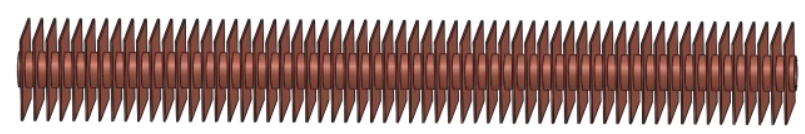

Fig. 3. Computational module of the heat exchanger.

\subsection{Numerical analysis}

The ANSYS Fluent commercial code was used to perform numerical simulations. The CFD solver was configured as pressure-based and the analysis were carried out in steady state. The solver employs an algorithm which belongs to a general class of methods called the projection method, where the constraint of mass conservation of the velocity field is achieved by solving a pressure equation. The pressure equation is derived from the continuity and the momentum equations in such a way that the velocity field, corrected by the pressure, satisfies the continuity. The solution process involves iterations in order to solve the nonlinear and coupled governing equations.

The mass-flow-inlet boundary condition with mass flow rate equal $0.02 \mathrm{~kg} / \mathrm{s}$, was specified at the inlet of the heating water. Moreover the k- $\varepsilon$ turbulence model was selected with the standard wall function and the turbulence intensity was $5 \%$. The outflow boundary condition was defined on the surface of water outflow.

The desorption process of the adsorption bed working cycle was simulated. Improvement of heat transfer conditions during desorption process will allow to decrease the hot water temperature which is necessary to well prepared the bed to the subsequent adsorption cycle. Therefore the carried out numerical simulations were focused on desorption process only, because the optimization of heat transfer in the adsorbent bed will allow to utilize the low grade thermal energy sources effectively. The temperature of the inlet hot water was $343 \mathrm{~K}$. Two cases were analysed: first was for coated 
bed construction and the second was for conventional bed with packed silica gel.

\section{Results and discussion}

Heat transfer between adjacent subdomains was modelled as conjugate heat transfer. The remaining walls were defined as adiabatic.

All figures are presented with the same temperatures range in order to compare the differences in the obtained temperature fields. The obtained temperature distributions in the computational domain of the heat exchanger are depicted for two cases in Figure 4.

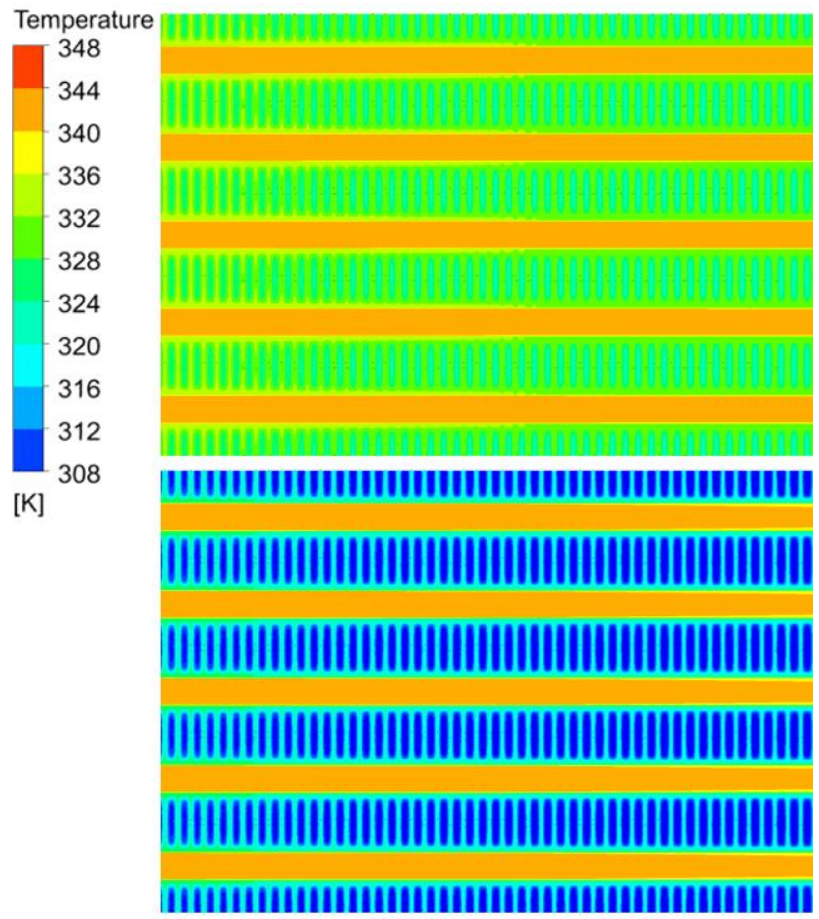

Fig. 4. The temperature distribution in the in longitudinal section of whole computational domain; top - case 1 with glue, bottom - case 2 without glue.

The intensification of the heat transfer between the heat exchanger surface and the coated bed is clearly visible. In consequence desorption in a coated bed will be performed more efficiency. Heat transfer in the conventional fixed bed is strongly limited by very low thermal conductivity of silica gel and high porosity of sorbent layer.

In Table 2, numerically determined average temperatures in particular subdomains of adsorption bed are presented.

Table 2. Comparison of Numerically Determined

Temperatures (w-water, s-silica gel, c-coated layer).

\begin{tabular}{|l|c|c|}
\hline $\begin{array}{c}\text { Average } \\
\text { variable }\end{array}$ & Coated bed & Fixed bed \\
\hline $\mathrm{T}_{\mathrm{W}}$ (in) & 343 & 343 \\
\hline $\mathrm{T}_{\mathrm{W}}$ (out) & 341.13 & 339.34 \\
\hline $\mathrm{T}_{\mathrm{S}}$ (in) & 322.40 & 302.43 \\
\hline $\mathrm{T}_{\mathrm{S}}$ (out) & 319.50 & 296.75 \\
\hline $\mathrm{T}_{\mathrm{W}}$ & 342.20 & 341.10 \\
\hline $\mathrm{T}_{\mathrm{S}}$ & 321.12 & 303.76 \\
\hline $\mathrm{T}_{\mathrm{c}}$ & 328.10 & - \\
\hline
\end{tabular}

Higher average temperatures in the silica gel volume are noticed for the coated bed construction, which confirms the positive effect of the coated layer on the desorption process.

The comparison of two cases reveals, that in the coated sorbent, higher temperatures during the desorption process at the inlet and outlet of the computational domain was noticed, respectively. It has been confirmed that the use of a glued layer results in a more intense heat transfer from water to the volume of silica gel. High thermal resistance, which is observed in fixed bed leads to the increase of desorption time, thus increasing of the energy input for the cooling production and lowering the COP of adsorption chiller.

\section{Conclusions}

The numerical analysis of heat transfer in two adsorption beds construction is presented in this paper. Numerical simulations under the same flow conditions were carried out, which allowed to indication of the crucial impact of the bed component's thermal parameters.

The influence of a coated sorbent layer on heat transfer intensification is investigated. The average temperature of silica gel volume in the coated bed case was $321.12 \mathrm{~K}$ and in the fixed bed case it was only $303.76 \mathrm{~K}$. The obtained temperature distributions confirm that the glued layer of sorbent contributed to the intensification of heat transfer from the hot water to the adsorption bed volume.

Numerical methods can be very useful in the optimization of adsorption bed parameters, because they allow determination of variables that are very difficult to define experimentally, such as temperature changes in the silica gel volume. However, empirical validation on a physical adsorption bed model is necessary in order to precisely define the boundary conditions of the numerical model.

\section{Acknowledgments}

Scientific work was performed within the project: "The development of innovative technology of adsorption chiller NETI ${ }^{\circ}$, using special, glued construction of the adsorption beds" (number: POIR.01.01.01-00-1659/15) it was partially supported by National Science Centre of Poland (Narodowe Centrum Nauki) grant number 2017/01/X/ST8/00019 as well as subsidies granted by the Faculty of Mathematics and Natural Sciences of Jan Dlugosz University in Czestochowa. The support is gratefully acknowledged.

\section{References}

1. B. B. Saha, S. Koyama, T. Kashiwagi, A. Akisawa, K. C. Ng, H. T. Chua, 2003, Int. J. Refrig. 26, 7, pp. 749-757 (2003)

2. K. Sztekler, W. Kalawa, W. Nowak, S. Stefański, J. Krzywanski, K. Grabowska, Proc. Experimental Fluid Mechanics 2017 (N. J. Dančová Petra, ed., Technical University of Liberec, pp. 650-653, 2017) 
3. J., Krzywanski, K. Grabowska, F. Herman, P. Pyrka, M. Sosnowski, T. Prauzner, W. Nowak, Energ Convers Manage, 153, pp. 313-322 (2017)

4. D. C. Wang, Z. Z. Xia, J. Y. Wu, R. Z. Wang, H. Zhai, W.D. Dou, Int J Refrig, 28, 7, pp. 1073-1083 (2005)

5. A.A. Askalany, S. K. Henninger, M. Ghazy, B. B. Saha, Appl Therm Eng 110, pp. 695-702 (2017)

6. Y. Jiang, T.S. Ge, R. Z. Wang, L. M. Hu, Int J Refrig 51, pp. 169-179 (2015)

7. K. Grabowska, J. Krzywanski, W. Nowak, M. Wesolowska, Energy 151, pp. 317-323 (2018)

8. Y. I. Aristov, I. S. Glaznev, I. S. Girnik, Energy 46, 1, pp. 484-492 (2012)

9. Q. W. Pan, R.Z. Wang, L.W. Wang, D. Liu, Int J Refrig 67, pp. 336-344 (2016)

10. A. Rezk, R. K. Al-Dadah, S. Mahmoud, A. Elsayed, Appl Therm Eng 53, 2, pp. 278-284 (2013)

11. J. Krzywanski, W. Nowak, Int J Heat Mass Transfer 94, pp. 327-334 (2016)

12. A. Gnatowski, M. Sosnowski, A. Pajdak, J. Sobczyk, Adv Sci Technol Res J. 12, 2, (2018)

13. M. Sosnowski, J. Krzywanski, K. Grabowska, R. Gnatowska, International Conference on Experimental Fluid Mechanics 2017 (P. Dančová, and J. Novosád, eds., pp. 589-594, Mikulov, 2017)

14. S. Jribi, T. Miyazaki, B.B. Saha, S. Koyama, S. Maeda, T. Maruyama, Int J Refrig 74, pp. 345353 (2017)

15. K. Grabowska, M. Sosnowski, J. Krzywanski, K. Sztekler, W. Kalawa, A. Zylka, W. Nowak, J. Therm. Sci. 27, 5, pp. 421-426 (2018)

16. M. Sosnowski, International Conference on Experimental Fluid Mechanics 2017 (P. Dančová, and N. J., eds., pp. 582-588, Mikulov, 2017)

17. M. Sosnowski, Engineering Mechanics 2018, (Svratka, pp. 801-804, 2018) 